Figure. Summary of AAU flares (observed data)

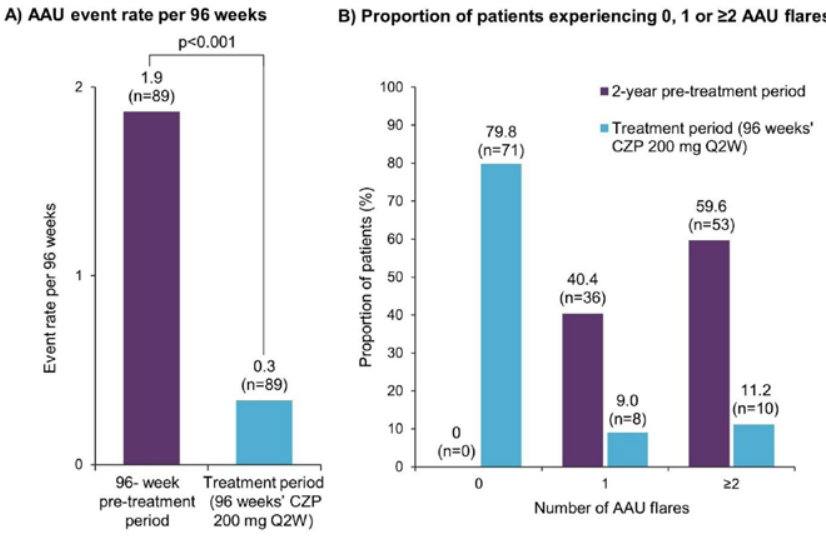

Treatment period: after start of study medication until Week 96 or discontinuation visit. Pre-treatment period: 24 months prior to treatment start. Flares on the same eye are combined and counted as one flare if the time interval Q2W through 96 weeks. a) Poisson regression analysis, with period (pre-/post-baseline) and axSpA disease duration as covariates and adjusting for the length of time in the pre- and post-baseline periods. AAU: acute anterior uveitis: CZP: certolizumab pegol; Q2W: every 2 weeks.

Table 1. Changes in axSpA disease activity to Week 96

\begin{tabular}{lccc}
\hline Disease activity measure & Week $\mathbf{0}$ & Week 48 & Week 96 \\
& $(\mathbf{n}=\mathbf{8 9})$ & $(\mathbf{n}=\mathbf{8 6})$ & $\mathbf{( n = 8 2 )}$ \\
\hline ASAS responder rates, $\mathrm{n}(\%)$ & & & \\
ASAS20 & $\mathrm{N} / \mathrm{A}$ & $65(75.6)$ & $62(75.6)$ \\
ASAS40 & $\mathrm{N} / \mathrm{A}$ & $46(53.5)$ & $48(58.5)$ \\
ASDAS, mean (SD) & $3.5(1.0)$ & $2.0(0.9)$ & $1.9(1.0)$ \\
BASDAl, mean (SD) & $6.5(1.5)$ & $3.3(2.1)$ & $3.0(2.1)$
\end{tabular}

Observed data are shown. Patients received CZP $400 \mathrm{mg}$ at Weeks $0 / 2 / 4$, then $200 \mathrm{mg}$ Q2W through 96 weeks. ASAS20/40: Assessment of SpondyloArthritis international Society 20\%/40\%; ASDAS: Ankylosing Spondylitis Disease Activity Score; axSpA: axial spondyloarthritis; BASDAI: Bath Ankylosing Spondylitis Disease Activity Index; CZP: certolizumab pegol; Q2W: every 2 weeks; SD: standard deviation.

Acknowledgements: This study was funded by UCB Pharma. Editorial services were provided by Costello Medical.

Disclosure of Interests: Irene van der Horst-Bruinsma Speakers bureau: AbbVie, BMS, MSD, Pfizer, UCB Pharma, Consultant of: AbbVie, Eli Lilly, MSD, Novartis, UCB Pharma, Grant/research support from: AbbVie, MSD, Pfizer, Rianne van Bentum: None declared, Frank Verbraak Speakers bureau: Bayer, IDxDR, Novartis, UMC, Consultant of: Bayer, Novartis, Grant/research support from: Bayer, Thomas Rath Speakers bureau: AbbVie, BMS, Chugai, Eli Lilly, MSD, Novartis, Pfizer, Roche, UCB Pharma, Consultant of: AbbVie, BMS, Chugai, Eli Lilly, MSD, Novartis, Pfizer, Roche, UCB Pharma, Bengt Hoepken Shareholder of: UBC Pharma, Employee of: UCB Pharma, Oscar Irvin-Sellers Shareholder of: UCB Pharma, Employee of: UCB Pharma, Thomas Kumke Shareholder of: UCB Pharma, Employee of: UCB Pharma, Lars Bauer Shareholder of: UCB Pharma, Employee of: UCB Pharma, Martin Rudwaleit Speakers bureau: AbbVie, Eli Lilly, Novartis, UCB Pharma, Consultant of: AbbVie, Celgene, Eli Lilly, Janssen, Novartis, UCB Pharma

DOI: 10.1136/annrheumdis-2021-eular.115

\section{POS0899 HOW DOES GENDER AFFECT SECUKINUMAB TREATMENT OUTCOMES AND RETENTION RATES IN PATIENTS WITH ANKYLOSING SPONDYLITIS? - REAL WORLD DATA FROM THE GERMAN AQUILA STUDY}

U. Kiltz ${ }^{1}$, J. Brandt-Juergens ${ }^{2}$, P. Kästner ${ }^{3}$, E. Riechers ${ }^{4}$, D. Peterlik ${ }^{5}$, H. P. Tony ${ }^{6}$. ${ }^{1}$ Rheumazentrum Ruhrgebiet / Ruhr-Universität Bochum, Rheumazentrum Ruhrgebiet, Herne, Germany; ${ }^{2}$ Rheumatologische Schwerpunktpraxis, Rheumatologische Schwerpunktpraxis, Berlin, Germany; ${ }^{3}$ Ambulantes Rheumazentrum, Ambulantes Rheumazentrum, Erfurt, Germany; ${ }^{4}$ Medizinische Hochschule Hannover, Klinik für Immunologie und Rheumatologie, Hannover, Germany; ${ }^{5}$ Novartis Pharma GmbH, Immunology, Hepatology \& Dermatology, Nuremberg, Germany; ${ }^{6}$ Medizinische Klinik II, Universitätsklinik, Rheumatology/ Immunology, Würzburg, Germany

Background: Current studies suggest that the phenotype of spondyloarthritis differs between genders and that this may influence the subsequent diagnostic approach and therapeutic decisions ${ }^{1}$. The German non-interventional study AQUILA provides real-world data on the influence of gender on therapeutic effectiveness and retention rate under treatment with secukinumab, a fully human monoclonal antibody that selectively inhibits interleukin-17A.
Objectives: The aim of this interim analysis is to describe selected baseline (BL) demographics, to evaluate secukinumab treatment outcomes on disease activity, global functioning and health and retention rate depending on the gender of AS patients.

Methods: AQUILA is an ongoing, multi-center, non-interventional study including more than 3000 patients with active AS or psoriatic arthritis. Patients were observed from BL up to week (w) 52 according to clinical routine. Real-world data was assessed prospectively and analyzed as observed. Validated questionnaires were used to collect data on disease activity (Bath Ankylosing Spondylitis Disease Activity Index, BASDAI), global functioning and health (Assessment of SpondyloArthritis-Health Index, ASAS-HI) and severity of depressive mood (Beck's Depression Inventory version II, BDI-II). Patient reported outcomes were reported using patient's global assessment (PGA). In addition, retention rates (time from study inclusion until premature secukinumab treatment discontinuation) were assessed through Kaplan-Meier plots. This interim analysis focuses on the subgroups of male and female AS patients.

Results: At BL, 683 AS patients were included: 59.7\% ( $n=408)$ male and $40.3 \%$ $(n=275)$ female. Demographic data (Table 1) of male and female AS patients differed numerically in the following parameters: proportion of obese patients, smokers, pretreatment with disease-modifying antirheumatic drugs (csDMARDs), and biologicals/biosimilars (b-bsDMARDs).

Mean BASDAI and PGA were comparable between male and female AS patients over time ( $0: 5.2$ at BL to 3.8 at w52, $9: 5.3$ at BL to 4.1 at w52 and 5.9 at BL to 4.1 at w52, 0 : 5.6 at BL to 4.3 at w52, respectively). Mean ASAS-HI over time was higher in women; nevertheless, improvements in global functioning were comparable for both genders from BL to week 52 (Fig. 1A). Severity of depressive mood was numerically lower in male patients; nevertheless, BDI-II reductions were comparable across the genders ( 11.2 at BL to 10.0 at w52, $9: 13.1$ at BL to 11.0 at w52). Secukinumab treatment retention rate for men was (not significantly) higher than for women (Fig. 1B). Conclusion: In a real-world setting, secukinumab improved disease activity, global functioning and severity of depressive mood in AS patients in both men and women. Women showed overall higher disease burden. Altogether, realworld data of this interim analysis are in line with those of Phase 3 studies and show that secukinumab is an effective treatment up to 52 weeks with high treatment retention rates, irrespective of gender.

\section{REFERENCES:}

[1] Landi, M., et al. Medicine (Baltimore) 95, e5652 (2016).

Table 1. Overview of baseline characteristics in AS patients depending on gender

\begin{tabular}{lcc}
\hline Demographics $^{*}$ & Male $(\mathbf{N}=\mathbf{4 0 8})$ & Female $(\mathbf{N}=\mathbf{2 7 5})$ \\
\hline Age, years & $45.6(12.1)$ & $47.8(12.2)$ \\
$\mathrm{BMI}, \mathrm{kg} / \mathrm{m}^{2}$ & $27.4(4.5)$ & $27.6(5.7)$ \\
$\mathrm{BMI}>25 \mathrm{to} \leq 30 \mathrm{~kg} / \mathrm{m}^{2}, \mathrm{n}(\%)$ & $178(45.1)$ & $88(32.4)$ \\
$\mathrm{BMl}>30 \mathrm{~kg} / \mathrm{m}^{2}, \mathrm{n}(\%)$ & $94(23.8)$ & $83(30.5)$ \\
$\mathrm{Smoker}, \mathrm{n}(\%)$ & $150(36.8)$ & $67(24.4)$ \\
$\mathrm{BASDAl}$ & $5.2(1.9)$ & $5.3(1.9)$ \\
$\mathrm{PGA}$ & $5.8(4.9)$ & $5.6(5.6)$ \\
$\mathrm{ASAS}-\mathrm{HI}$ & $7.4(3.5)$ & $8.2(3.5)$ \\
BDI-II & $11.2(10.2)$ & $13.1(13.0)$ \\
Medication prior to secukinumab initiation, $\mathrm{n}(\%):$ & \\
NSAID & $330(80.9)$ & $222(80.7)$ \\
csDMARD & $145(35.5)$ & $137(49.8)$ \\
b-bsDMARD & $249(61.0)$ & $190(69.1)$ \\
\hline
\end{tabular}

${ }^{*}$ variables given as mean (SD)
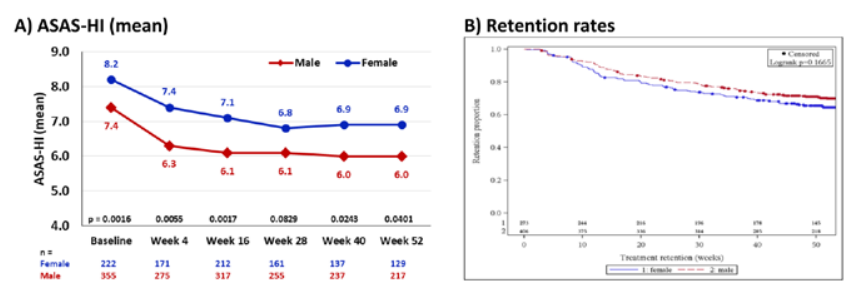

Figure 1. Global functioning and secukinumab treatment retention in AS patients stratified by genderNote: P-values are of exploratory nature

Disclosure of Interests: Uta Kiltz Consultant of: AbbVie, Biocad, Chugai, Eli Lilly, Gruenenthal, Janssen, MSD, Novartis, Pfizer, Roche, UCB, Grant/research support from: AbbVie, Biogen, Novartis, Pfizer, Jan Brandt-Juergens Consultant of: Abbvie, Affibody, BMS, Gilead, Janssen, Lilly, Medac, MSD, Novartis, Pfizer, Roche, Sanofi-Aventis, UCB, Peter Kästner Consultant of: Chugai, Novartis, Elke Riechers Consultant of: AbbVie, Chugai, Novartis, UCB, Grant/research support from: AbbVie, Chugai, Lilly, Janssen, Novartis, Pfizer, Roche, UCB, Daniel Peterlik 
Employee of: Novartis Pharma GmbH, Hans-Peter Tony Consultant of: AbbVie, Astra-Zeneca, BMS, Chugai, Janssen, Lilly, MSD, Novartis, Pfizer, Roche, Sanofi DOI: 10.1136/annrheumdis-2021-eular.141

\section{POS0900 SECUKINUMAB 150 MG PROVIDES SUSTAINED IMPROVEMENT IN SIGNS AND SYMPTOMS OF NON-RADIOGRAPHIC AXIAL SPONDYLOARTHRITIS: 2-YEAR RESULTS FROM THE PREVENT STUDY}

D. Poddubnyy ${ }^{1}$, A. Deodhar ${ }^{2}$, X. Baraliakos ${ }^{3}$, R. Blanco ${ }^{4}$, E. Dokoupilova ${ }^{5}$, S. Hall ${ }^{6}$, A. Kivitz ${ }^{7}$, M. G. H. Van de Sande ${ }^{8}$, A. Stefanska ${ }^{9}$, P. Pertel ${ }^{10}$, H. Richards ${ }^{10}$, J. Braun ${ }^{11} .{ }^{1}$ Charité - Universitätsmedizin Berlin, German Rheumatism Research Centre, Berlin, Germany; ${ }^{2}$ Oregon Health \& Science University, Division of Arthritis and Rheumatic Diseases, Portland, United States of America; ${ }^{3}$ Rheumazentrum Ruhrgebiet, Rheumatology Division, Herne, Germany; ${ }^{4}$ Hospital University Marqués de Valdecilla, IDIVAL, Division of Rheumatology, Santander, Spain; ${ }^{5}$ Medical Plus, s.r.o., Uherske Hradiste, Masaryk University, Department of Pharmaceutical Technology, Faculty of Pharmacy, Brno, Czech Republic; ${ }^{6}$ Monash University, Department of Medicine, Melbourne, Australia; ${ }^{7}$ Altoona Center for Clinical Research, Clinical Research Division, Pennsylvania, United States of America; ${ }^{8}$ Amsterdam UMC, University of Amsterdam, Amsterdam Rheumatology and Immunology Center, Amsterdam, Netherlands; ${ }^{9}$ Novartis Ireland Limited, Immunology, Hepatology and Dermatology, Dublin, Ireland; ${ }^{10}$ Novartis Pharma AG, Immunology, Hepatology and Dermatology, Basel, Switzerland; ${ }^{11}$ Rheumazentrum Ruhrgebiet, Herne, and Ruhr-University Bochum, Department of Rheumatology, Bochum, Germany

Background: Axial spondyloarthritis (axSpA) is an inflammatory disease characterised by chronic back pain, and it comprises radiographic axSpA and non-radiographic axSpA (nr-axSpA). ${ }^{1}$ Secukinumab (SEC) $150 \mathrm{mg}$, with (LD) or without loading (NL), dose significantly improved the signs and symptoms of patients with nr-axSpA in the PREVENT (NCT02696031) study through Week $52 .{ }^{2}$

Objectives: To report the long-term clinical efficacy and safety of secukinumab from the PREVENT study through 2 years.

Methods: A detailed study design, key primary and secondary endpoints have been reported previously. ${ }^{2}$ In total, 555 patients fulfilling ASAS criteria for axSpA plus abnormal C-reactive protein (CRP) and/or MRI, without evidence of radiographic changes in sacroiliac (SI) joints according to modified New York Criteria for AS were randomised (1:1:1) to receive SEC $150 \mathrm{mg}$ with $\mathrm{LD}$, NL, or placebo (PBO) at baseline. LD patients received SEC $150 \mathrm{mg}$ at Weeks 1, 2, 3, and 4, and then every 4 weeks (q4wk) starting at Week 4 . NL patients received SEC $150 \mathrm{mg}$ at baseline and PBO at weeks 1, 2, and 3, and then $150 \mathrm{mg} \mathrm{q} 4 \mathrm{wk} .90 \%$ patients were anti-tumour necrosis factor (anti-TNF) naïve, 57\% had elevated CRP and $73 \%$ had evidence of SI joint inflammation on MRI. All images were assessed centrally before inclusion. All patients continued to receive open-label SEC $150 \mathrm{mg}$ treatment after Week 52. Efficacy assessments through Week 104 included ASAS40 in anti-TNFnaïve patients, ASAS40, BASDAI change from baseline, BASDAI50, ASAS partial remission, and ASDAS-CRP inactive disease in the overall population. The safety analyses included all patients who received $\geq 1$ dose of study treatment for the entire treatment period up to Week 104. Data are presented as observed.

Results: Overall, 438 patients completed 104 weeks of study: 78.9\% (146/185; LD), $77.7 \%$ (143/184; NL) and 80.1\% (149/186; PBO). Efficacy results at Week 52 were sustained through Week 104 and are reported in the Table 1. The safety profile was consistent with the previous reports with no deaths reported during the entire treatment period up to Week $104 .^{2}$

Conclusion: Secukinumab $150 \mathrm{mg}$ demonstrated sustained improvement in the signs and symptoms of patients with nr-axSpA through 2 years. Secukinumab was well tolerated with no new or unexpected safety signals. REFERENCES:

[1] Strand V, et al. J Clin Rheumatol. 2017; 23(7):383-91.

[2] Deodhar A, et al. Arthritis Rheumatol. 2020. Online ahead of print.

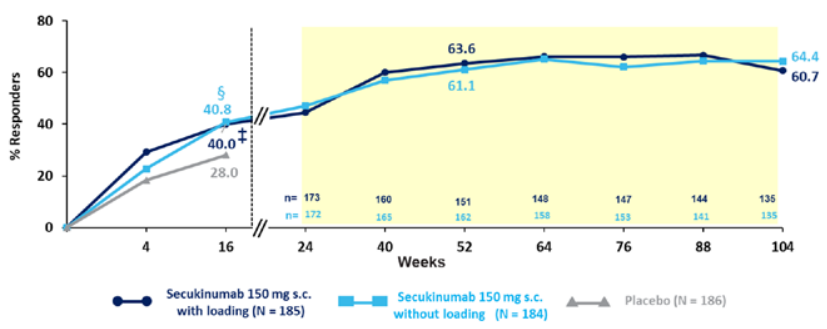

$\S \mathrm{p}<0.01$ and $\ddagger \mathrm{p}<0.05 \mathrm{vs}$ placebo (unadjusted p-values at Week 16). Data presented as non-responder imputation till week 16 an as observed from Week 24 to Week 104.At Week 52 all patients remaining on blinded treatment switched to open-label secukinumab.
ASAS, Assessment of SpondyloArthritis Intermational Society; $N$, total number of patients randomised; $n$, number of evaluable patients including those who switched to open label secukinumab or standard of care after Week 20 . After Week 52 , only patients who

Figure 1. ASAS40 response was maintained through Week 104 in the overall population
Table 1. Summary of clinical efficacy (Observed data)

\begin{tabular}{|c|c|c|c|c|}
\hline Endpoints & Week & $\begin{array}{c}\text { SEC } 150 \mathrm{mg} \\
\text { LD } \\
(\mathrm{N}=185)\end{array}$ & $\begin{array}{l}\text { SEC } 150 \mathrm{mg} \mathrm{NL} \\
(\mathrm{N}=184)\end{array}$ & $\begin{array}{c}\text { PBO-SEC } \\
-\quad 150 \mathrm{mg} \\
(\mathrm{N}=186)\end{array}$ \\
\hline $\begin{array}{l}\text { *ASAS40 in anti-TNF-naïve } \\
\text { patients, } n / M(\%)\end{array}$ & $\begin{array}{l}52^{\mathrm{a}} \\
104\end{array}$ & $\begin{array}{l}90 / 137(65.7) \\
78 / 123(63.4)\end{array}$ & $\begin{array}{l}95 / 145(65.5) \\
83 / 123(67.5)\end{array}$ & $\begin{array}{l}85 / 151(56.3) \\
83 / 134(61.9)\end{array}$ \\
\hline $\begin{array}{l}\text { BASDAI change from baseline, } \\
\text { mean } \pm \text { SD }\end{array}$ & $\begin{array}{l}52^{\mathrm{a}} \\
104\end{array}$ & $\begin{array}{l}-3.7 \pm 2.8 \\
-4.1 \pm 2.6\end{array}$ & $\begin{array}{l}-3.7 \pm 2.6 \\
-3.9 \pm 2.6\end{array}$ & $\begin{array}{l}-3.3 \pm 2.4 \\
-3.7 \pm 2.5\end{array}$ \\
\hline BASDAI50, n/M (\%) & $\begin{array}{l}52^{\mathrm{a}} \\
104\end{array}$ & $\begin{array}{l}90 / 153(58.8) \\
88 / 137(64.2)\end{array}$ & $\begin{array}{l}92 / 163(56.4) \\
84 / 136(61.8)\end{array}$ & $\begin{array}{l}90 / 161(55.9) \\
87 / 142(61.3)\end{array}$ \\
\hline ASAS partial remission, & $\begin{array}{l}52^{\mathrm{a}} \\
104\end{array}$ & $\begin{array}{l}46 / 152(30.3) \\
51 / 137(37.2)\end{array}$ & $\begin{array}{l}56 / 163(34.4) \\
50 / 135(37.0)\end{array}$ & $\begin{array}{l}46 / 161(28.6) \\
50 / 142(35.2)\end{array}$ \\
\hline n/M (\%) & & & & \\
\hline $\begin{array}{l}\text { ASDAS CRP inactive disease, } \\
\mathrm{n} / \mathrm{M}(\%)\end{array}$ & $\begin{array}{l}52^{\mathrm{a}} \\
104\end{array}$ & $\begin{array}{l}49 / 152(32.2) \\
50 / 132(37.9)\end{array}$ & $\begin{array}{l}58 / 163(35.6) \\
53 / 133(39.8)\end{array}$ & $\begin{array}{l}48 / 160(30.0) \\
53 / 142(37.3)\end{array}$ \\
\hline
\end{tabular}

${ }^{*}$ For anti-TNF-naïve patients, N=164, LD; 166, NL; 171, PBO-SEC. ${ }^{a}$ total number of evaluable patients including open-label SEC and standard of care (SOC; 2 patients in LD, 1 patient in $\mathrm{NL}$ continued on SOC). After Week 52, only patients who continued to receive open-labe SEC are presented.ASAS, Assessment of SpondyloArthritis International Society; ASDAS, Ankylosing Spondylitis Disease Activity Score; BASDAI, Bath Ankylosing Spondylitis Disease Activity Index; $\mathrm{M}$, number of patients with evaluation; $\mathrm{N}$, total randomised patients; $n$, number of patients who are responders; SD, standard deviation

Disclosure of Interests: Denis Poddubnyy Speakers bureau: AbbVie, BMS, Eli Lilly, MSD, Novartis, Pfizer, UCB, Consultant of: AbbVie, Biocad, BMS, Eli Lilly, Gilead, MSD, Novartis, Pfizer, Samsung Bioepis, UCB, Grant/research suppor from: AbbVie, MSD, Novartis, Pfizer, Atul Deodhar Speakers bureau: AbbVie Amgen, Boehringer Ingelheim, Bristol Myer Squibb (BMS), Eli Lilly, GSK, Janssen, Novartis, Pfizer, and UCB, Consultant of: AbbVie, Amgen, Boehringer Ingelheim, Bristol-Myers Squibb, Celgene, Eli Lilly, Gilead, GSK, Janssen, Novartis Pfizer, and UCB, Grant/research support from: AbbVie, Eli Lilly, GSK, Novartis, Pfizer, and UCB, Xenofon Baraliakos Speakers bureau: AbbVie, BMS, Celgene, Chugai, MSD, Novartis, Pfizer, and UCB, Consultant of: AbbVie, BMS Celgene, Chugai, Galapagos, Gilead, MSD, Novartis, Pfizer, and UCB, Grant/ research support from: AbbVie and Novartis, Ricardo Blanco Speakers bureau AbbVie, Pfizer, Roche, Bristol-Myers, Janssen, UCB pharma and MSD and Eli Lilly, Consultant of: AbbVie, Pfizer, Roche, Bristol-Myers, Janssen, UCB pharma and MSD, Grant/research support from: AbbVie, MSD, and Roche, Eva Dokoupilova Grant/research support from: AbbVie, Affibody AB, Eli Lilly, Galapagos Gilead, GSK, Hexal AG, MSD, Novartis, Pfizer, R-Pharm, Sanofi-Aventis, and UCB, Stephen Hall Speakers bureau: Novartis, Merck, Janssen, Pfizer, Eli Lilly, and UCB, Consultant of: Novartis, Merck, Janssen, Pfizer, Eli Lilly, and UCB Grant/research support from: AbbVie, UCB, Janssen, and Merck, Alan Kivitz Shareholder of: Pfizer, Sanofi, Novartis, Amgen, GlaxoSmithKline, Gilead Sciences, Inc., Speakers bureau: Celgene, GlaxoSmithKline, Eli Lilly, Merck, Novartis, Pfizer, Sanofi, Genzyme, Flexion, AbbVie, UCB, Consultant of: AbbVie, Boehringer Ingelheim, Flexion, Janssen, Pfizer, Sanofi, Regeneron, SUN Pharma Advanced Research, Gilead Sciences, Inc., Marleen G.H. van de Sande Speakers bureau: Novartis, MSD, Consultant of: Abbvie, Novartis, Eli Lily, Grant/ research support from: Novartis, Eli Lilly, Janssen, UCB, Anna Stefanska Shareholder of: Novartis, Employee of: Novartis, Patricia Pertel Shareholder of: Novartis, Employee of: Novartis, Hanno Richards Shareholder of: Novartis, Employee of: Novartis, Juergen Braun Speakers bureau: Abbvie (Abbott), Amgen, BMS Boehringer, Celgene, Celltrion, Centocor, Chugai, EBEWE Pharma, Medac MSD (Schering-Plough), Mundipharma, Novartis, Pfizer (Wyeth), Roche, SanofiAventis and UCB pharma, Eli Lilly, Consultant of: Abbvie (Abbott), Amgen, BMS, Boehringer, Celgene, Celltrion, Centocor, Chugai, EBEWE Pharma, Medac MSD (Schering-Plough), Mundipharma, Novartis, Pfizer (Wyeth), Roche, SanofiAventis and UCB, Eli Lilly, Grant/research support from: Abbvie (Abbott), Amgen BMS, Boehringer, Celgene, Celltrion, Centocor, Chugai, Medac, MSD (Schering-Plough), Mundipharma, Novartis, Pfizer (Wyeth), Roche, Sanofi-Aventis and UCB, Eli Lilly

DOI: 10.1136/annrheumdis-2021-eular.143

\begin{tabular}{l|l}
\hline POS0901 & IXEKIZUMAB SHOWS A DISTINCT PATTERN OF \\
PAIN IMPROVEMENT BEYOND INFLAMMATION IN \\
RADIOGRAPHIC AXIAL SPONDYLOARTHRITIS
\end{tabular}

K. De Vlam ${ }^{1}$, G. Gallo², P. J. Mease ${ }^{3}$, P. Rahman ${ }^{4}$, V. Krishnan ${ }^{2}$, D. Sandoval ${ }^{2}$, C. Y. Lin ${ }^{2}$, R. Bolce ${ }^{2}$, P. G. Conaghan ${ }^{5} .{ }^{1}$ University Hospital Leuven, Rheumatology, Leuven, Belgium; ${ }^{2}$ Eli Lilly and Company, Lilly Corporate Centre, Indianapolis, United States of America; ${ }^{3}$ Swedish Medical Center/Providence St. Joseph Health and University of Washington, Rheumatology, Seattle, United States of America; ${ }^{4}$ Memorial University of Newfoundland, Medicine, St. John's, Canada; ${ }^{5}$ University of Leeds, School of Medicine, Leeds, United Kingdom

Background: The efficacy of ixekizumab (IXE) in biologic-naïve patients with radiographic axial spondyloarthritis ( $\mathrm{r}$-axSpA) has been previously presented using traditional axSpA outcome measures, such as BASDAI and ASAS. 